\section{Growing Degree-day Models for Predicting Lowbush Blueberry (Vaccinium angustifolium Ait.) Ramet Emergence, Tip Dieback, and Flowering in Nova Scotia, Canada}

\author{
Scott N. White \\ Department of Plant Agriculture, University of Guelph, 1132 Pictou Road, \\ East Mountain, Nova Scotia B6L 2N5, Canada
}

\author{
Nathan S. Boyd ${ }^{1}$ \\ Department of Environmental Science, Nova Scotia Agricultural College, \\ Truro, Nova Scotia, Canada, B2N 5E3
}

\author{
Rene C. Van Acker \\ Department of Plant Agriculture, University of Guelph, Guelph Ontario, \\ Canada, N1G $2 \mathrm{Wl}$
}

Additional index words. thermal model, emergence model, apical shoot abortion, flowering, rhizomatous shrub

\begin{abstract}
Experiments were established to evaluate the suitability of growing degree-day (GDD, $T_{\text {base }}=0{ }^{\circ} \mathrm{C}$ ) models for predicting emergence, tip dieback, and flowering of lowbush blueberry ramets in Nova Scotia, Canada. Data for model development were collected from quadrats established in several non-bearing and bearing blueberry fields throughout the dominant blueberry production areas in northern and central Nova Scotia. Blueberry ramets emerged between 222 and 265 GDD (6 May to 14 May) and reached $90 \%$ emergence between 619 and 917 GDD (7 June to 5 July). Emergence continued to slowly increase until late summer or early fall. Tip dieback began between 598 and 792 GDD (14 June to 21 June) and duration of this phase depended on whether lateemerging ramets developed to tip dieback. A four-parameter Weibull and a three-parameter Gompertz equation adequately explained cumulative blueberry ramet emergence and cumulative ramets at tip dieback as functions of GDD in the non-bearing year, respectively. The four-parameter Weibull function also explained the relationship between cumulative flowering ramets and GDD in the bearing year. Flowering ramets were first observed between 376 and 409 GDD (19 May to 30 May) in the bearing year. Model predictions for initiation of emergence, tip dieback, and flowering were 243, 692, and 389 GDD, respectively. Models were validated with independent data sets collected throughout northern and central Nova Scotia. The relationship between the percentage of open flowers on individual ramets and GDD in the bearing year was well described by a Gaussian model at two sites with a predicted peak number of open flowers between 552 and 565 GDD.
\end{abstract}

The lowbush blueberry is a native, perennial berry species in Nova Scotia. Commercial fields are not planted but are developed

\footnotetext{
Received for publication 1 Mar. 2012. Accepted for publication 15 May 2012.

Funding for this work was provided by the Natural Sciences and Engineering Research Council Industrial Postgraduate Scholarship and DuPont.

We acknowledge the assistance of summer students in the Vegetation Management Research Program at the Nova Scotia Agricultural College, Truro, Nova Scotia, Canada. We also acknowledge Bragg Lumber Company and Purdy Resources for providing field sites.

This article is a portion of a thesis submitted by Scott White in partial fulfillment of the requirements for a PhD degree at the University of Guelph. ${ }^{1}$ To whom reprint requests should be addressed; e-mailnboyd@nsac.ca.
}

on abandoned farmland or cleared woodland where native blueberry stands already exist (Agriculture and Agri-Food Canada, 2005; Barker et al., 1964). These stands are composed of distinct and variable clones that spread by underground rhizomes (Glass and Percival, 2000; Hall and Aalders, 1961). The crop is managed on a 2-year cycle. Plants are pruned to ground level to promote vegetative growth in the first, or non-bearing, year. Flowering, fruit development, and harvest occur in the second, or bearing, year.

Growth and development in the non-bearing year consists of ramet emergence from underground rhizomes and growth of these ramets until abortion of the apical meristem (tip dieback) stimulates development of floral buds in late summer and fall (Aalders and Hall, 1964; Barker and Collins, 1963; Hall and Ludwig, 1961). Ramets generally emerge rapidly from mid-May until late June (Eggert, 1957). Initiation of emergence is largely determined by temperature and date of spring pruning (Eaton and White, 1960; Trevett, 1962). Modern blueberry production systems in Nova Scotia typically use fall pruning after harvest in the bearing year instead of spring pruning in the non-bearing year as described by Trevett (1962). Because pruning does not actually occur in the non-bearing year, initiation of ramet emergence in this phase of the production cycle in Nova Scotia is likely regulated primarily by air or soil temperatures in early spring.

Vegetative growth of emerged ramets is most rapid in warm temperatures and long days (Hall and Ludwig, 1961; Kender, 1967). Tip dieback is not thought to be induced by external stimuli (Barker and Collins, 1963), but temperature is an important factor affecting apical shoot abortion in some woody species (Millington, 1963; Suzuki, 1991). Abortion of the apical meristem in lowbush blueberry is a prerequisite to flower bud initiation in the non-bearing year (Bell, 1950; Bell and Burchill, 1955). Therefore, the time period between ramet emergence and tip dieback is crucial in terms of establishment of both crop density and biomass that will support the development of flower buds in the bearing year. Extensive stands of lowbush blueberries in certain regions of Nova Scotia regularly fail to produce acceptable fruit yields, primarily as a result of limitations imposed on growth and development by low temperatures in both the non-bearing and bearing years (Hall et al., 1964, 1970). Therefore, rates of ramet emergence and development to tip dieback in the non-bearing year may simply be a function of temperature within a given growing season.

Growth and development in the bearing year are comprised of leaf expansion and flowering in spring (Bell and Burchill, 1955; Hall et al., 1979) and fruit development and harvest by late summer. Flowering is delayed by cool temperatures (Bell, 1953), but flower buds typically swell in early May when air temperatures exceed $10{ }^{\circ} \mathrm{C}$ for more than $4 \mathrm{~d}$ (Hall et al., 1979). The bloom period is from 1 to 3 weeks (Chiasson and Argall, 1996; Wood, 1961) and timely movement of honeybee hives during bloom is important for ensuring adequate pollination.

Most management practices in lowbush blueberry production are governed by the timing of ramet emergence or specific ramet growth stages. Blueberry growers rely on calendar dates (e.g., Aalders et al., 1972) or general references to crop development stage (Anonymous, 2011) for timing these management practices. Relating blueberry ramet emergence and growth stage to GDDs should reduce the variability in timing of these processes observed between field locations and growing seasons (Bell, 1950, 1953; Wood, 1961). GDD models have been useful for predicting harvest dates of highbush blueberry cultivars in Michigan (Carlson and Hancock, 1991) and cumulative flowering of 'rabbiteye' blueberries (NeSmith and Bridges, 1992). 
Similar models have not been developed for lowbush blueberries in Nova Scotia, but GDD models to predict maturity of perennial forage crops in this region have been successful (Bootsma, 1984). The effects of weather conditions have proven inconsistent in terms of predicting lowbush blueberry fruit production in Eastern Canada (Hall et al., 1982), but no attempts have been made to model growth and development of this species as functions of GDDs.

The lowbush blueberry acreage in Nova Scotia increased by $31 \%$ between 1992 and 2003 and is expected to exceed 40,000 acres by 2013 (Strik and Yarborough, 2005). This increased acreage, in combination with management practices driven by the growth and development of a native species in response to environmental conditions, gives immediate applicability to predictive models in crop management. The objectives of this study were to 1) develop GDD models to predict emergence and tip dieback of lowbush blueberry ramets in the non-bearing year and flowering in the bearing year; and 2) validate these models with independent data sets collected throughout northern and central Nova Scotia.

\section{Materials and Methods}

Site selection. Blueberry ramet emergence and development were monitored in six commercial lowbush blueberry fields in Nova Scotia between 2009 and 2011. Site locations were chosen based on proximity to large blueberry acreages in northern and central Nova Scotia. All sites were initially established in fields that had been pruned by flail mowing at the end of the previous season. Two sites were established in the non-bearing year near Collingwood in 2009 (Purdy and Wyvern) with an additional non-bearing year site near Collingwood in 2010 (Pigeon Hill) (Table 1). Non-bearing year sites were also established near Londonderry in 2010 and Mount Thom and North River in 2011 (Table 1). Sites established in non-bearing fields in 2009 and 2010 were retained for bearing year data collection in 2010 and 2011, respectively (Table 1).

Weather data. Hourly air temperature at each site was monitored using temperature loggers (HOBO Pro V2; Onset Computer Corporation, Cape Cod, MA). Data loggers were attached to wooden stakes and were located $\approx 0.5 \mathrm{~m}$ above the soil surface. $\mathrm{Re}$ gional air temperature data from the nearest Environment Canada weather station were used to supplement field-based temperature data so that GDDs could be calculated starting on 1 Apr. (day of year 91). Cumulative GDDs were calculated using the formula:

$$
G D D=\sum_{i=1}^{n}\left(T_{\text {mean }}-T_{\text {base }}\right)
$$

where $T_{\text {mean }}$ is the mean daily air temperature, $\mathrm{T}_{\text {base }}$ is the lowest air temperature at which we assume blueberry emergence or development will not occur, and $n$ is the number of days over which GDDs are calculated. In this equation, $G D D=0$ if $T_{\text {mean }} \leq$ $T_{\text {base }}$, similar to the approach used by Gordon and Bootsma (1993) for determining annual GDD accumulations in Atlantic Canada. Rainfall data for each site were obtained from the nearest Environment Canada weather station. Mean daily air temperature and rainfall data for non-bearing and bearing year sites are provided in Figures 1 and 2.

Emergence and development data. Emergence and development of blueberry ramets (e.g., individual shoots) to the tip dieback stage were monitored in four $0.09-\mathrm{m}^{2}$ quadrats established at non-bearing year sites in 2009, 2010, and 2011 (Table 1). Quadrats were placed in separate clones where possible, but individual clones could not be clearly identified at the time of quadrat placement at all study sites. Newly emerged blueberry ramets were counted and marked with colored elastic bands once or twice weekly from early May until late October. Dead ramets were counted to estimate ramet mortality, and elastics were removed. Ramets at tip dieback were counted and tagged with metal wire to prevent double-counting. Ramets were considered to have reached tip dieback when the black tip associated with death of the apical meristem was observed (Barker and Collins, 1963). In the bearing year, blueberry ramets with at least one open flower were counted as flowering and marked with metal wire once or twice weekly starting in early spring and continuing until no new ramets with open flowers were observed. Flowers were considered open when internal structures of the blossom (e.g., pistils and stamens) were visible to the naked eye. Counts for ramet emergence, ramets at tip dieback, and flowering were expressed on a percent cumulative scale for modeling purposes. Six additional $0.09-\mathrm{m}^{2}$ quadrats were established at bearing year sites in 2011 to estimate the total number of open flowers per blueberry ramet during the bloom period. Ten blueberry ramets in each quadrat were tagged before the beginning of flowering, and the total number of open flowers on each tagged ramet was counted twice weekly until the end of the bloom period. Data for each of the 10 tagged ramets per quadrat were combined to obtain the mean percent of open flowers per quadrat on each counting date. These data are presented as the mean percent of the total number of open flowers per ramet.

Development of growing degree-day models. Cumulative blueberry ramet emergence, ramets at tip dieback, and flowering ramets were plotted as functions of GDD. Fitting of nonlinear equations as well as parameter estimates for these equations was conducted using the Gauss-Newton algorithm in PROC NLIN of the SAS system for Windows Version 9.2 (SAS Institute, Cary, NC). Percent cumulative blueberry ramet emergence (Y) was related to cumulative GDD with a Weibull equation of the form:

$$
Y=k\left[1-\exp \left(-b(G D D-m)^{c}\right)\right]
$$

where $\mathrm{Y}$ is percent cumulative emergence at any given GDD, $k$ is the theoretical maximum percent cumulative emergence, $b$ is the rate of increase in percent cumulative emergence, $m$ is the lag phase until the onset of emergence, and $c$ is a shape parameter (Martinson et al.,

Table 1. Description of study sites used to collect data for calibration and validation of growing degree-day models developed for lowbush blueberry in Nova

\begin{tabular}{|c|c|c|c|c|c|c|c|}
\hline Site-year & Production year & Latitude & Longitude & Elevation (m) & Soil type ${ }^{y}$ & Soil $\mathrm{pH}^{\mathrm{x}}$ & Soil \%OM \\
\hline Purdy-2009 & Non-bearing & $45^{\circ} 35^{\prime} 34.904^{\prime \prime} \mathrm{N}$ & $63^{\circ} 50^{\prime} 49.932^{\prime \prime} \mathrm{W}$ & 114 & Sandy loam & 4.8 & 5.5 \\
\hline Wyvern-2009 & Non-bearing & $45^{\circ} 32^{\prime} 57.042^{\prime \prime} \mathrm{N}$ & $63^{\circ} 55^{\prime} 56.311^{\prime \prime} \mathrm{W}$ & 238 & Sandy loam & 4.6 & 6.0 \\
\hline Pigeon Hill-2011 & Bearing & & & 190 & Dancy IOan & 4.8 & 10.0 \\
\hline $\begin{array}{l}\text { Londonderry-2010 } \\
\text { Londonderry-2011 }\end{array}$ & $\begin{array}{l}\text { Non-bearing } \\
\text { Bearing }\end{array}$ & $45^{\circ} 26^{\prime} 21.280^{\prime \prime} \mathrm{N}$ & $63^{\circ} 32^{\prime} 44.640^{\prime \prime} \mathrm{W}$ & 62 & Sandy loam & 4.6 & 5.8 \\
\hline $\begin{array}{l}\text { Londonderry-2011 } \\
\text { Mount Thom-2011 }\end{array}$ & Non-bearing & $45^{\circ} 29^{\prime} 30.373^{\prime \prime} \mathrm{N}$ & $62^{\circ} 59^{\prime} 25.200^{\prime \prime} \mathrm{W}$ & 229 & Sandy loam & 4.8 & 7.4 \\
\hline
\end{tabular}
Scotia, Canada. ${ }^{2}$

${ }^{2}$ Data for development and validation of blueberry ramet emergence and tip dieback models were collected at non-bearing year sites. Data for development and validation of blueberry flowering models were collected at bearing year sites. Non-bearing year sites established in 2009 and 2010 were retained for bearing year data collection in 2010 and 2011, respectively.

ySoil type for Purdy-2009, Purdy-2010, Wyvern-2009, Wyvern-2010, Pigeon Hill-2010, and Pigeon Hill-2011 obtained from Nowland and MacDougall (1973); soil type for Londonderry-2010, Londonderry-2011, North River-2011, and Mount Thom-2011 obtained from Webb et al. (1991).

${ }^{\mathrm{x}} \mathrm{pH}$ and $\% \mathrm{OM}$ (\% organic matter) determined from four soil cores taken to a depth of $10 \mathrm{~cm}$ at each site. Cores were combined to form a composite sample for each site. Composite samples submitted to the Nova Scotia Department of Agriculture Provincial Analytical Laboratory for analysis.

${ }^{\mathrm{w}}$ Soil $\mathrm{pH}$ and $\% \mathrm{OM}$ data for this site were unavailable. 

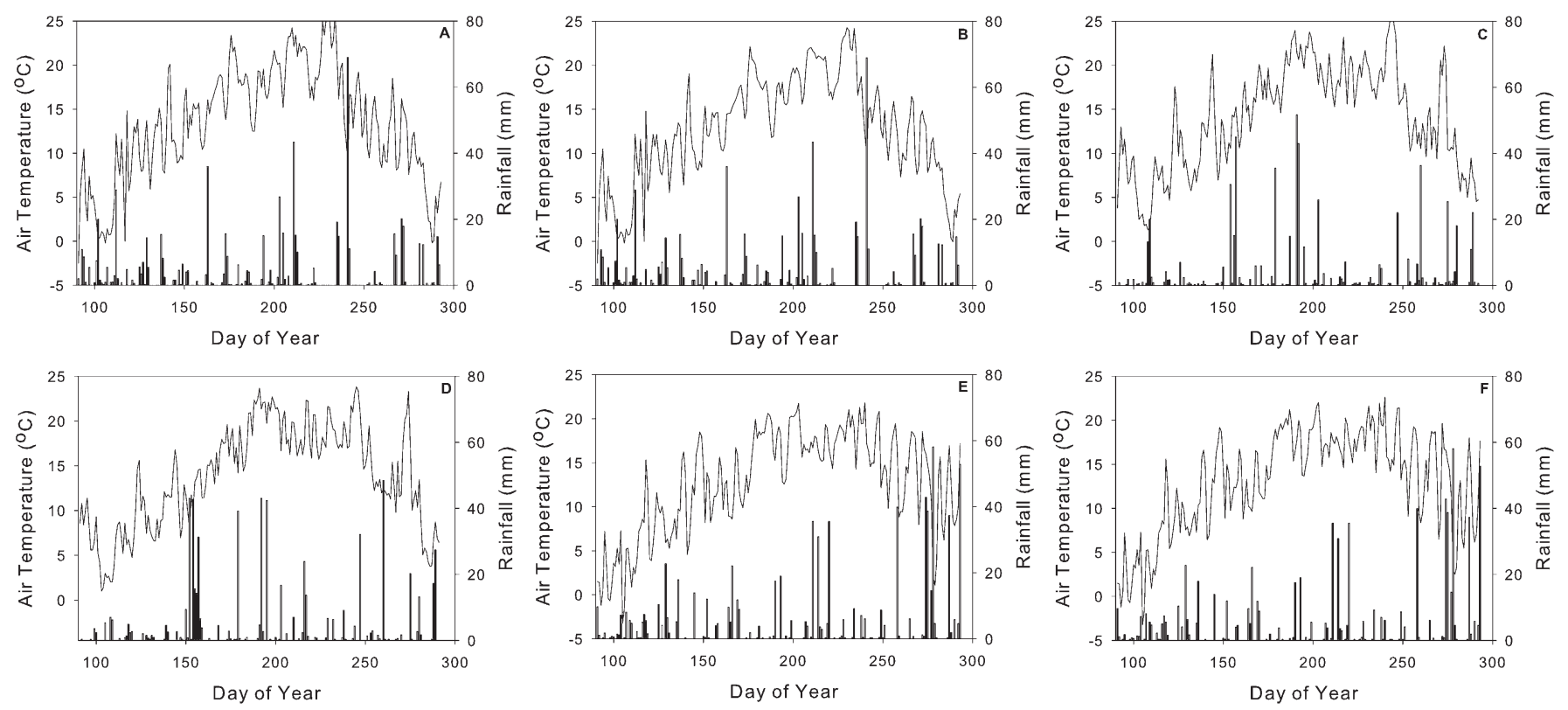

Fig. 1. Daily mean air temperature (line) and rainfall (bars) during blueberry emergence and development to tip dieback at (A) Purdy in 2009 , (B) Wyvern in 2009 , (C) Pigeon Hill in 2010, (D) Londonderry in 2010, (E) Mount Thom in 2011, and (F) North River in 2011. Mean daily air temperature was obtained from HOBO temperature loggers placed $0.5 \mathrm{~m}$ above the soil surface at each site. Rainfall data for Purdy in 2009, Wyvern in 2009, and Pigeon Hill in 2010 were

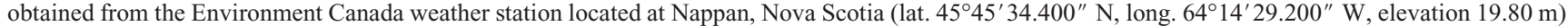
Rainfall data for Londonderry in 2010, Mount Thom in 2011, and North River in 2011 were obtained from the Environment Canada weather station located at Debert, Nova Scotia (lat. $45^{\circ} 25^{\prime} 00.000 \mathrm{~N}$, long. $63^{\circ} 28^{\prime} 00.000^{\prime \prime} \mathrm{W}$, elevation of $37.50 \mathrm{~m}$ ).
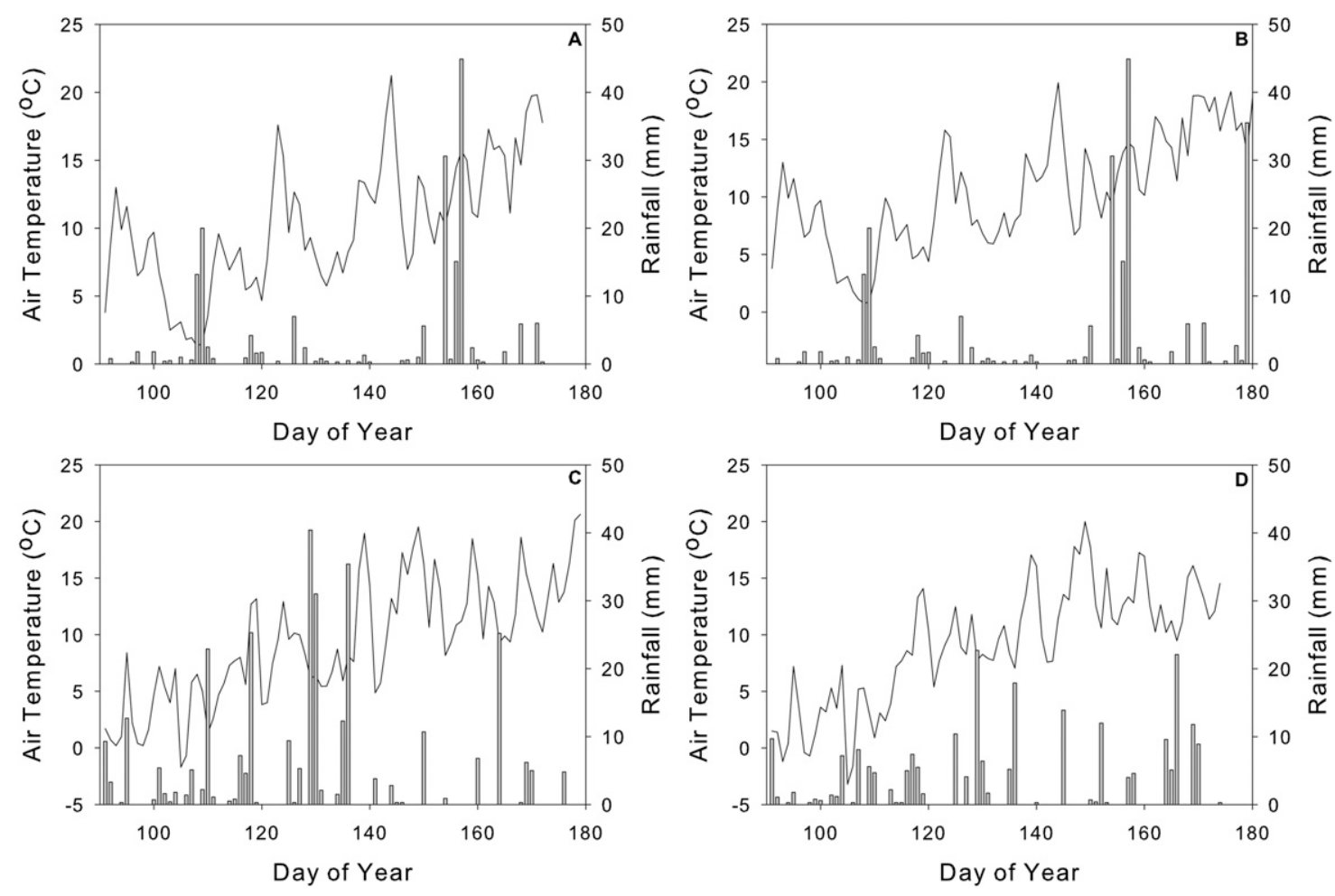

Fig. 2. Mean daily air temperature (line) and rainfall (bars) during wild blueberry flowering at (A) Purdy in 2010, (B) Wyvern in 2010, (C) Pigeon Hill in 2011, and (D) Londonderry in 2011. Mean daily air temperature was obtained from HOBO temperature loggers placed $0.5 \mathrm{~m}$ above the soil surface at each site. Rainfall data for Purdy in 2010, Wyvern in 2010, and Pigeon Hill in 2011 were obtained from the Environment Canada weather station located at Nappan, Nova Scotia (lat. $45^{\circ} 45^{\prime} 34.400^{\prime \prime} \mathrm{N}$, long. $64^{\circ} 14^{\prime} 29.200^{\prime \prime} \mathrm{W}$, elevation $19.80 \mathrm{~m}$ ). Rainfall data for Londonderry in 2011 were obtained from the Environment Canada weather station located at Debert, Nova Scotia (lat. $45^{\circ} 25^{\prime} 00.000^{\prime \prime}$ N, long. $63^{\circ} 28^{\prime} 00.000^{\prime \prime}$ W, elevation of $37.50 \mathrm{~m}$ ).

2007). The base air temperature for blueberry ramet emergence was determined by iterating a series of base temperatures $\left(0\right.$ to $5^{\circ} \mathrm{C}$ in $1-{ }^{\circ} \mathrm{C}$ intervals) in Eq. 2 until the best fit was obtained between percent cumulative ramet emergence and cumulative GDDs (Izquierdo et al., 2009). The best fit was obtained for $T_{\text {base }}$ equal to $0{ }^{\circ} \mathrm{C}$. Given no current biological justification for using an alternative $T_{\text {base }}, 0^{\circ} \mathrm{C}$ was chosen based on best fit and simplicity in data calculation in both the current study and for potential end-users of the proposed model. 
Percent cumulative blueberry ramets at tip dieback (Y) was related to cumulative GDD with a Gompertz equation of the form:

$$
Y=k \times \exp [-\exp (-b(G D D-m))]
$$

where $Y$ is percent cumulative ramets at tip dieback, $k$ is the theoretical maximum percent cumulative ramets at tip dieback, $b$ is the rate of increase in percent cumulative ramets at tip dieback, and $m$ is the inflection point of the curve on the $\mathrm{x}$-axis (Dorado et al., 2008). Percent cumulative flowering ramets in the bearing year was related to cumulative GDD using the Weibull equation described previously, where $Y$ is percent cumulative flowering ramets, $k$ is the theoretical maximum percent cumulative flowering ramets, $b$ is the rate of increase in percent cumulative flowering, $m$ is the lag phase until the onset of flowering, and $c$ is a shape parameter.

The mean percent of total open flowers was related to cumulative GDD with a Gaussian equation of the form:

$$
Y=k\left[\exp \left(-0.5\left(\frac{G D D-m}{b}\right)^{2}\right)\right]
$$

where $Y$ is the mean percent of total open flowers, $k$ is the theoretical maximum percent of total open flowers, $m$ is the GDD at the maximum percent of total open flowers, and $b$ is a shape parameter. Using the iterative proce-

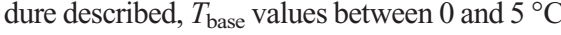
provided similar fit of the proposed tip tieback and flowering models (based on criteria described subsequently). A $T_{\text {base }}$ value of $0{ }^{\circ} \mathrm{C}$ was, therefore, maintained for GDD calculations to allow for use of the same GDD scale when comparing thermal requirements for emergence, tip dieback, and flowering.

Assessing fit and validation of growing degree-day models. Goodness of fit for all models was determined by calculating the coefficient of determination $\left(R^{2}\right)$ and adjusted coefficient of determination $\left(R^{2}\right.$ Adj $)$ :

$$
R^{2}=1-\frac{\sum\left(y_{\text {obs }}-y_{\text {pred }}\right)^{2}}{\sum\left(y_{\text {obs }}\right)^{2}}
$$

and

$$
R_{A d j}^{2}=1-\frac{n\left(1-R^{2}\right)}{n-p}
$$

where $\mathrm{y}_{\mathrm{obs}}$ and $\mathrm{y}_{\text {pred }}$ are the observed and predicted values, respectively, $n$ is the number of observations, and $p$ is the number of parameters in the regression equation (Bowley, 2008) and the root mean square error (RMSE):

$$
R M S E=\sqrt{(1 / n) \sum_{i=1}^{n}\left(y_{\text {obs }}-y_{\text {pred }}\right)^{2}}
$$

Goodness of model fit was based on low RMSE and $R^{2}$ Adj values close to 1 , and these formulae and criteria were used when assessing fit of all models proposed in this study.

Models for percent cumulative blueberry ramet emergence and percent cumulative ramets at tip dieback were validated with emergence and tip dieback data from two non-bearing year sites that were not used for model calibration (Wyvern in 2009 and North River in 2011) (Table 1). The model for predicting percent cumulative flowering ramets was validated at two sites in the Collingwood area (Wyvern in 2010 and Pigeon Hill in 2011) (Table 1). Emergence and development data were expressed as percent cumulative emergence and development and plotted against cumulative GDD. Emergence and development predictions were calculated with the models and plotted against actual emergence and development, and the $R^{2}$ Adj and RMSE described previously were used to assess agreement between observed data and model predictions. The Gaussian model fit to the percent of total open flowers was not
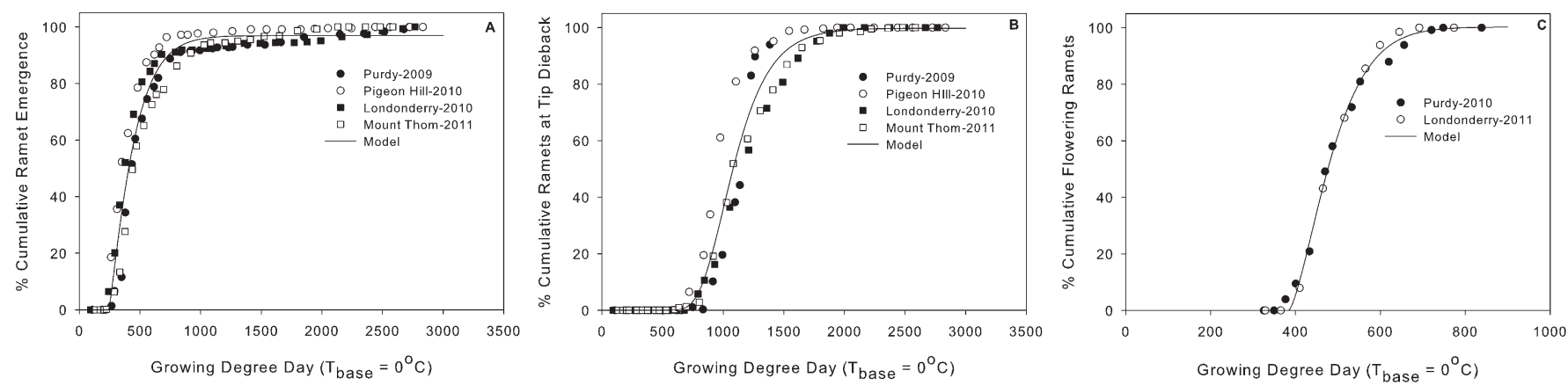

Fig. 3. (A) Percent cumulative lowbush blueberry ramet emergence, (B) percent cumulative ramets at tip dieback, and (C) percent cumulative ramets with open flowers in relation to cumulative growing degree-days (GDDs) calculated from air temperature $\left(\mathrm{T}_{\text {base }}=0{ }^{\circ} \mathrm{C}\right)$ at sites used for model calibration in Nova Scotia, Canada. Symbols represent the mean of four observations. Lines are fitted regression equations. A Weibull equation of the form $Y=k\left[1-\exp \left(-b(G D D-m)^{c}\right)\right]$ was fit to percent cumulative ramet emergence and percent cumulative flowering ramets. A Gompertz equation of the form $Y=k \times \exp [-\exp (-b(G D D-m))]$ was fit to percent cumulative ramets at tip dieback. Parameter estimates and goodness of fit statistics for each regression equation are given in Table 2.
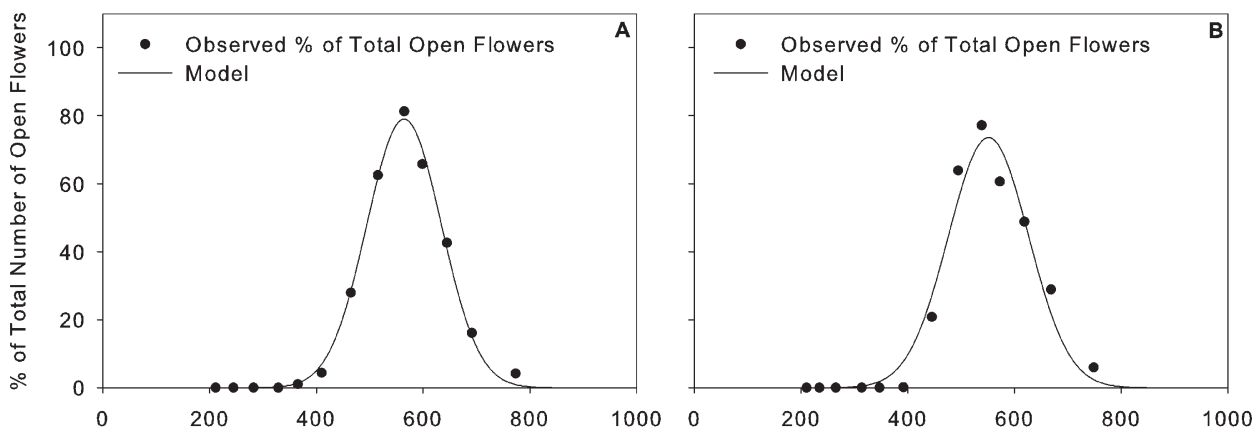

Growing Degree Day $\left(T_{\text {base }}=0^{\circ} \mathrm{C}\right)$

Fig. 4. Percent of total number of open blueberry flowers in relation to cumulative growing degree-days (GDDs) calculated from air temperature $\left(\mathrm{T}_{\text {base }}=0{ }^{\circ} \mathrm{C}\right)$ at (A) Londonderry in 2011 and (B) Pigeon Hill in 2011. Symbols are the mean of six observations. Lines are a fitted Gaussian equation of the form $Y=k\left[\exp \left(-0.5\left(\frac{G D D-m}{b}\right)^{2}\right)\right]$. Parameter estimates and goodness-of-fit statistics for the Gaussian equation fit to data for each site are given in Table 4. 
Table 2. Parameter estimates and goodness of fit statistics for proposed Weibull and Gompertz equations describing the relationship between growing degree-days (GDDs) calculated from air temperature $\left(\mathrm{T}_{\text {base }}=0^{\circ} \mathrm{C}\right)$ and percent cumulative lowbush blueberry ramet emergence, percent cumulative ramets at tip dieback, and percent cumulative flowering ramets in Nova Scotia, Canada. ${ }^{z}$

\begin{tabular}{|c|c|c|c|c|c|c|c|c|}
\hline \multirow[b]{2}{*}{ Model } & \multirow[b]{2}{*}{ Site-year } & \multirow[b]{2}{*}{ Equation } & \multicolumn{4}{|c|}{ Model parameters ${ }^{y}$} & \multirow[b]{2}{*}{$R_{\text {Adj }}^{2}$} & \multirow[b]{2}{*}{$\mathrm{RMSE}^{\times}$} \\
\hline & & & $k$ & $b$ & $m$ & $c$ & & \\
\hline Percent cumulative ramets at tip dieback & $\begin{array}{l}\text { Purdy-2009 } \\
\text { Pigeon Hill-2010 } \\
\text { Londonderry-2010 } \\
\text { Mount Thom-2011 }\end{array}$ & Gompertz & $\begin{array}{c}99.7882 \\
(1.4101)\end{array}$ & $\begin{array}{c}0.00486 \\
(0.000343)\end{array}$ & $\begin{array}{l}1005.4 \\
(10.5541)\end{array}$ & - & 0.99 & 6.61 \\
\hline Percent cumulative flowering ramets & $\begin{array}{l}\text { Purdy-2010 } \\
\text { Londonderry- } 2011\end{array}$ & Weibull & $\begin{array}{l}100.2 \\
(1.3937)\end{array}$ & $\begin{array}{c}0.000950 \\
(0.00154)\end{array}$ & $\begin{array}{l}383.7 \\
(8.1976)\end{array}$ & $\begin{array}{c}1.4553 \\
(0.1645)\end{array}$ & 0.99 & 2.33 \\
\hline 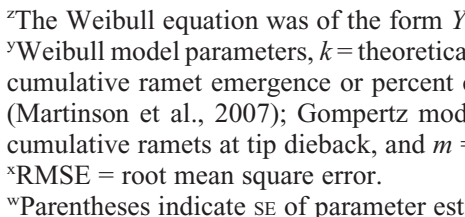 & $\begin{array}{l}k[1-\exp (-b(G D D- \\
\text { laximum percent cum } \\
\text { nulative flowering ran } \\
\text { parameters, } k=\text { theor } \\
\text { nflection point of the c }\end{array}$ & $\begin{array}{l}\left.\left.n)^{c}\right)\right] \text { and th } \\
\text { tive ramet } \\
\text { ts, } m=\text { the } \\
\text { ical maxim } \\
\text { rve on the } x\end{array}$ & $\begin{array}{l}\text { Jompertz e } \\
\text { ergence or p } \\
\text { phase unt } \\
\text { percent cl } \\
\text { kis (Dorado }\end{array}$ & $\begin{array}{l}\text { ion was of th } \\
\text { nt cumulativ } \\
\text { onset of en } \\
\text { ative ramets } \\
\text { 1., 2008). }\end{array}$ & $\begin{array}{l}\text { form } Y=k> \\
\text { lowering ram } \\
\text { gence or flo } \\
\text { tip dieback }\end{array}$ & $\begin{array}{l}\mathrm{xp}[-\exp \\
b=\text { rate } \\
\text { ing, and } \\
=\text { rate o }\end{array}$ & $\begin{array}{l}b(G D D \\
\text { increase } \\
=\text { shape } \\
\text { ncrease }\end{array}$ & $\begin{array}{l}m))] . \\
\text { percent } \\
\text { irameter } \\
\text { percent }\end{array}$ \\
\hline
\end{tabular}

validated as a result of lack of additional siteyears of data.

\section{Results}

General trends in emergence, tip dieback, and flowering. Blueberry ramets emerged between 222 and 265 GDD (6 May to 14 May) at all study sites (Fig. 3A). Emergence up to $90 \%$ was rapid but was followed by a slower emergence period that delayed peak emergence until 2132 to 2768 GDD (13 Sept. to 20 Oct.) (Fig. 3A). Survival of emerged ramets in the non-bearing year was greater than $90 \%$ at all sites (data not shown). Ramets were first observed at tip dieback between 598 and 792 GDD (14 June to 21 June) (Fig. 3B), which coincided with $72 \%$ to $96 \%$ blueberry ramet emergence. Duration of tip dieback was 42 to 119 calendar days and the percent of ramets at tip dieback peaked between 1529 and 2480 GDD (29 July to 11 Oct.) (Fig. 3B). Blueberry flowering in the bearing year began between 376 and 409 GDD (19 May to 30 May) and continued for 21 to 42 calendar days after initiation (Fig. 3C). The percentage of flowering ramets peaked between 692 and 748 GDD (16 June to 17 June) (Fig. $3 \mathrm{C}$ ), but the maximum percentage of total open flowers was recorded between 538 and 564 GDD (7 June) (Fig. 4). Less than $5 \%$ of the total number of open flowers remained by 748 to 773 GDD (23 June) (Fig. 4).

Development of growing degree-day models. Plotting ramet emergence, ramets at tip dieback, and flowering as functions of GDD generally reduced the variability between sites observed when data were plotted as a function of day of year (data not shown). The proposed models provided good fit to the field data and accurately predicted cumulative emergence, ramets at tip dieback, and flowering as functions of cumulative GDD (Fig. 3; Table 2). Model predictions for the initiation

Table 3. Estimated growing degree-days (GDDs) calculated from air temperature $\left(\mathrm{T}_{\text {base }}=0{ }^{\circ} \mathrm{C}\right)$ to reach $10 \%, 50 \%, 90 \%$, and $95 \%$ cumulative lowbush blueberry ramet emergence, percent cumulative ramets at tip dieback, and percent cumulative flowering ramets in Nova Scotia, Canada.

\begin{tabular}{llrrrr}
\hline & & \multicolumn{3}{c}{ Percent cumulative } \\
\cline { 3 - 5 } Model & & Equation & & \multicolumn{1}{c}{50} & 90 \\
\cline { 3 - 5 } Percent cumulative ramet emergence & Weibull & 276 & 407 & 734 & 928 \\
Percent cumulative ramets at tip dieback & Gompertz & 834 & 1082 & 1473 & 1626 \\
Percent cumulative flowering ramets & Weibull & 410 & 477 & 595 & 636 \\
\hline
\end{tabular}

${ }^{\mathrm{z}} \mathrm{GDD}$ estimates from calibrated Weibull and Gompertz equations described in Table 2.

Table 4. Parameter estimates and goodness of fit statistics for the Gaussian model describing the relationship between growing degree-days (GDDs) calculated from air temperature $\left(\mathrm{T}_{\text {base }}=0{ }^{\circ} \mathrm{C}\right)$ and percent of the total number of open flowers on lowbush blueberry ramets in Nova Scotia, Canada. ${ }^{z}$

\begin{tabular}{llcccc}
\hline & \multicolumn{3}{c}{ Model parameters $^{\mathrm{y}}$} & & \\
\cline { 2 - 5 } Site-year & $k$ & $b$ & $R_{\text {Adj }}$ & RMSE $^{\mathrm{x}}$ \\
\hline Londonderry-2011 & 78.9965 & 69.9381 & 564.5 & 0.99 & 1.85 \\
& $(1.5143)^{\mathrm{w}}$ & $(1.6720)$ & $(1.6552)$ & & 5.24 \\
Pigeon Hill-2011 & 73.5606 & 75.1617 & 551.6 & 0.97 & $(5.3029)$ \\
& $(4.0392)$ & $(5.3868)$ & & \\
\hline
\end{tabular}

zThe Gaussian model was of the form $Y=k\left[\exp \left(-0.5\left(\frac{G D D-m}{b}\right)^{2}\right)\right]$.

${ }^{y}$ Gaussian model parameters, $k=$ theoretical maximum percent of total open flowers, $b=$ shape parameter, and $m=$ GDD at the maximum percent of total open flowers (e.g., peak bloom).

${ }^{x} \mathrm{RMSE}=$ root mean square error.

wParentheses indicate SE of parameter estimates.

of emergence and tip dieback in the nonbearing year were 243 and 692 GDD, respectively, whereas 389 GDDs were predicted to accumulate before the initiation of flowering in the bearing year. Model predictions for $10 \%$, $50 \%, 90 \%$, and $95 \%$ emergence, ramets at tip dieback, and flowering are provided in Table 3. Both the Weibull and Gaussian models gave similar predictions for the initiation of flowering, and the Gaussian model predicted the maximum percentage of total open flowers (e.g., peak bloom) by 552 and 565 GDD at Pigeon Hill and Londonderry, respectively, in 2011 (Fig. 4; Table 4). According to the Gaussian model, the bloom period lasted for just over 400 GDDs at the study sites used to develop the model in 2011 (Fig. 4).
Model validation. Model predictions for blueberry ramet emergence, ramets at tip dieback, and flowering agreed quite closely with the observed values (Fig. 5), indicating good performance of these models for predicting emergence and development of lowbush blueberry ramets in Nova Scotia. All models had high $R^{2}$ Adj and low RMSE (Table 5), indicating that temperature is likely the dominant factor affecting emergence and development of lowbush blueberry ramets in Nova Scotia. The proposed emergence model predicted a slightly faster rate of emergence at North River in 2011 than was observed at this site, but the onset of ramet emergence was accurately predicted at both North River in 2011 and Wyvern in 2009 (Fig. 5A-B). The 

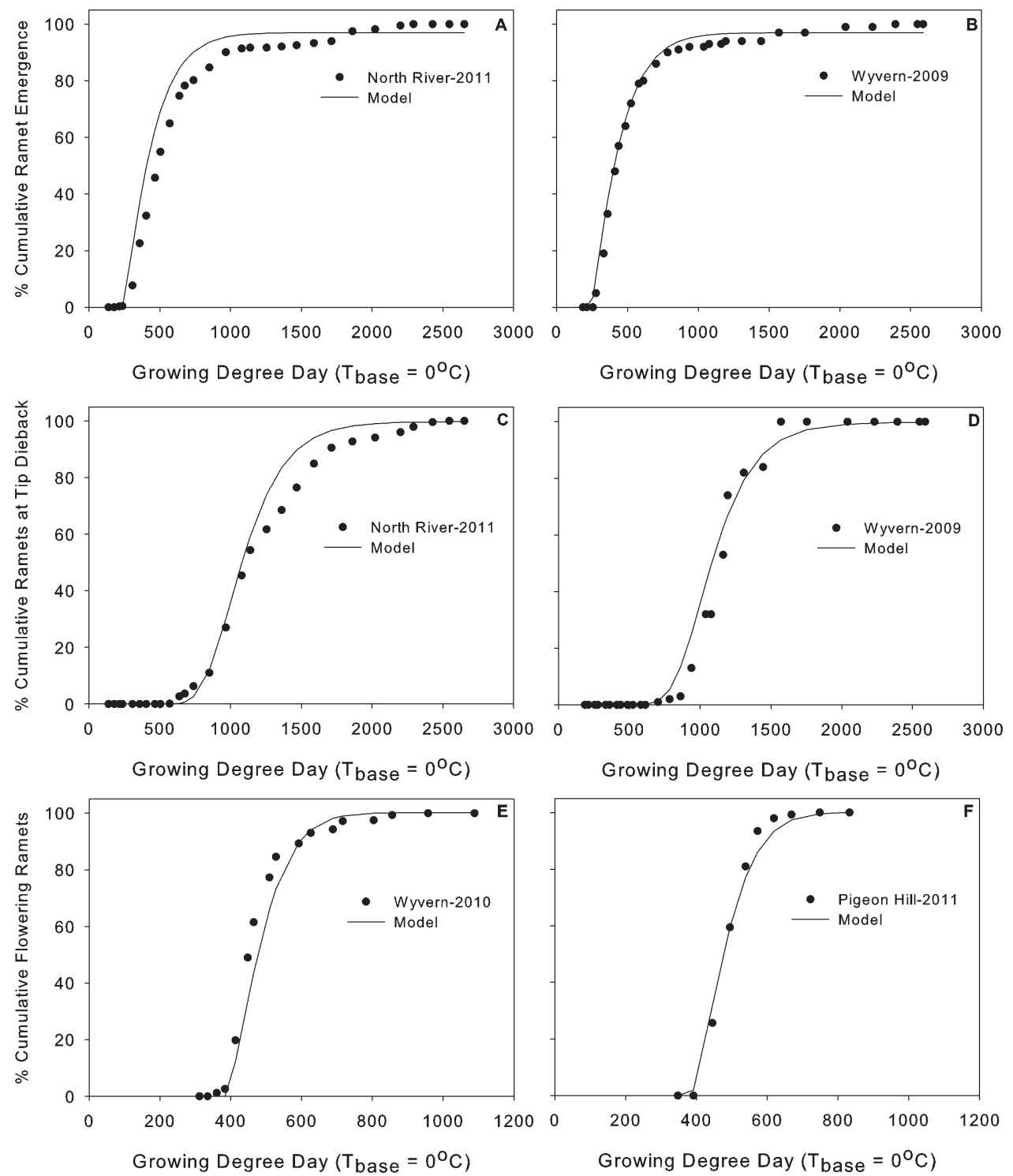

Fig. 5. (A-B) Observed and model predicted percent cumulative lowbush blueberry ramet emergence, (C-D) observed and model predicted percent cumulative lowbush blueberry ramets at tip dieback, and ( $\mathbf{E}-\mathbf{F})$ observed and model predicted percent cumulative flowering lowbush blueberry ramets in relation to growing degree-days (GDDs) calculated from air temperature $\left(\mathrm{T}_{\text {base }}=0{ }^{\circ} \mathrm{C}\right)$. Symbols are the mean of four observations, except at North River in 2011 where symbols are the mean of three observations. Lines are calibrated model predictions. The calibrated model for predicting percent cumulative ramet emergence and percent cumulative flowering ramets was a Weibull equation of the form $Y=k\left[1-\exp \left(-b(G D D-m)^{c}\right)\right]$. The calibrated model for predicting percent cumulative ramets at tip dieback was a Gompertz equation of the form $Y=k \times \exp [-\exp (-b(G D D-m))]$. Goodness-of-fit statistics for assessing agreement between observed and model predicted values are given in Table 5.

Table 5. Goodness-of-fit statistics for validation of proposed Weibull and Gompertz models for predicting the relationship between growing degree-days (GDDs) calculated from air temperature $\left(\mathrm{T}_{\text {base }}=0^{\circ} \mathrm{C}\right)$ and percent cumulative lowbush blueberry ramet emergence, percent cumulative ramets at tip dieback, and percent cumulative flowering ramets in Nova Scotia, Canada.

\begin{tabular}{lllcc}
\hline Model validated & Site-year & Equation & $R^{2}$ Adj & RMSE $^{z}$ \\
\hline Percent cumulative ramet emergence & North River-2011 & Weibull & 0.99 & 4.12 \\
& Wyvern-2009 & & 0.99 & 1.68 \\
Percent cumulative ramets at tip dieback & North River-2011 & Gompertz & 0.99 & 5.33 \\
& Wyvern-2009 & & 0.99 & 5.57 \\
Percent cumulative flowering ramets & Wyvern-2010 & Weibull & 0.99 & 7.34 \\
& Pigeon Hill-2011 & & 0.99 & 3.71 \\
\hline
\end{tabular}

${ }^{\mathrm{2}} \mathrm{RMSE}=$ root mean square error.

proposed tip dieback model predicted a slightly faster rate of tip dieback development at North River in 2011 and slightly earlier onset of this developmental phase at Wyvern in 2009 but predicted values were in close agreement with observed values at both sites (Fig. 5C-D; Table 5). Model predictions from the Weibull function used to predict flowering were in close agreement with observed flowering at both Wyvern in 2010 and Pigeon Hill in 2011 (Fig. 5E-F; Table 5).

\section{Discussion}

The pattern of blueberry ramet emergence observed in our study was similar to that reported for lowbush blueberry after burning of a Pinus banksiana stand in Manitoba (Hoefs and Shay, 1981). Observations from managed lowbush blueberry stands, however, report a much shorter emergence period (Eggert, 1957; Trevett, 1962). Duration of blueberry ramet emergence is thought to be regulated by apical dominance (Kender, 1968; Trevett, 1962). The onset of the slow emergence period observed in our study coincided with the initial detection of dead ramets, so it seems likely that new ramets emerged throughout the latter portion of the season simply in response to a release of apical dominance. Matlack et al. (1993) also reported 
that death of dominant meristems was required for shoot regeneration in black huckleberry (Gaylussacia baccata), a rhizomatous shrub very similar in growth form to lowbush blueberries.

Previous reports describing the onset and duration of tip dieback vary in consistency with our observations. Eggert (1957) reported both a later initiation of tip dieback and a much shorter duration of this developmental phase in burn-pruned blueberry clones in Maine. Timing and duration of tip dieback in burned plots in Manitoba and New Brunswick, however, were similar to that reported in the current study (Barker and Collins, 1963; Hoefs and Shay, 1981). Duration of tip dieback development in our study seemed to be affected by the tendency of later-emerging ramets to transition to this developmental stage. In some years (e.g., Purdy in 2009), many later-emerging ramets did not exhibit tip dieback, whereas in other years (e.g., North River in 2011), later-emerging ramets followed a developmental pattern similar to earlier-emerging ramets. Ramets emerging after $90 \%$ emergence generally remained much shorter than those emerging earlier (based on visual observation), but the requirement for a critical level of vegetative growth before tip dieback development is generally unaccepted (Barker and Collins, 1963). Poor growth and development of blueberry ramets occurs under shaded conditions (Hall, 1958; Hall and Ludwig, 1961), so shading by earlier emerging ramets may have affected growth and development of later emerging ramets in some of the quadrats. In the end, the contribution of ramets emerging late in the non-bearing year to final yield in the bearing year is unclear, and some emphasis should be placed on determining the survival and contribution of these ramets to flowering and fruit production in the bearing year.

The development of GDD models for lowbush blueberry is a major step forward in terms of improving the ability to predict emergence and development of this species. Lowbush blueberry ramet emergence as a function of GDDs was very similar across sites (Fig. 3A), and validation of the proposed model indicated good agreement between model predictions and field observations (Fig. 5A-B). Important herbicides such as hexazinone are applied pre-emergence to blueberries to prevent unacceptable crop injury (Jensen, 1985). This gives the model use in predicting the application timing of hexazinone and other pre-emergence herbicides. Moisture was not limiting during the emergence period at any of the study sites (Figs. 1 and 2). This may have facilitated the relatively uniform emergence across study sites, but the effects of limited soil moisture on vegetative growth of the lowbush blueberry are generally minimal (Benoit et al., 1984; Glass et al., 2005). Moisture conditions in this study were also typical for early spring in Nova Scotia and results from this study should be applicable to most growing seasons in this region.

Accumulation of GDDs was a good predictor of tip dieback because model predictions from the proposed Gompertz model agreed quite closely with the field observations used to validate the model (Fig. 5C-D). Although other factors can affect apical shoot abortion in blueberry (Hall and Ludwig, 1961; Kender, 1967) and other woody species (Barros and Neill, 1987; Junttila, 1976), our data indicate that temperature alone is adequate for predicting tip dieback in blueberry under field conditions in Nova Scotia. Fertility recommendations for blueberries are based on nutrient levels in leaf samples collected at $90 \%$ to $100 \%$ tip dieback in the non-bearing year (Smagula and Yarborough, 2010), so leaf samples should be collected $\approx 1600$ GDD in non-bearing fields in Nova Scotia (95\% tip dieback prediction; Table 3). In terms of pest management, tolerance of lowbush blueberry to herbicides in the nonbearing year tends to vary with the developmental stage of ramets at the time of herbicide application (N.S. Boyd, unpublished data). Combining predictions of ramet emergence with predictions of tip dieback development in the non-bearing year will be useful in future evaluations of new herbicides for managing increasingly diverse weed populations (Jensen and Yarborough, 2004).

Temperature is an important factor affecting opening of lowbush blueberry flower buds in spring (Hall et al., 1979; Wood, 1961) and our results indicate that it is the main factor driving the rate of blueberry flowering in the field in Nova Scotia. Predictions from our proposed Weibull model were in close agreement with field observations (Fig. 5E-F) and can be used to facilitate disease monitoring at early bloom and improve timing of bearing-year hexazinone applications (Delbridge et al., 2011; Jensen, 2002). When combined with the results from the Gaussian model (Fig. 4; Table 4), both the onset and duration of flowering can be predicted and used to improve pollination through the proper timing of pollinator introduction and removal from a given field.

\section{Conclusions}

The results from this study provide strong evidence that temperature is one of the most important factors regulating the emergence and development of lowbush blueberry ramets in Nova Scotia. The GDD models presented can be used to accurately predict blueberry emergence, tip dieback, and flowering in Nova Scotia. These models have use in the timing of pest, fertility, and pollinator management during the 2-year lowbush blueberry production cycle. Additional emergence and development data sets should be collected throughout regions of Nova Scotia outside the range of this study to provide further validation or improvement of the models. Lowbush blueberry acreages in other provinces in Atlantic Canada have increased substantially over the past 20 years (Strik and Yarborough, 2005). Attempts to validate the proposed models in these regions as well as other important production regions such as Maine will be important for assessing the applicability of the models outside of Nova Scotia.

\section{Literature Cited}

Aalders, L.E. and I.V. Hall. 1964. A comparison of flower-bud development in the lowbush blueberry, Vaccinium angustifolium Ait. under greenhouse and field conditions. Proc. Amer. Soc. Hort. Sci. 85:281-284.

Aalders, L.E., L.P. Jackson, B.G. Penney, A.F. Rayment, R. Stark, and I.V. Hall. 1972. Selection of an 'optimum' time to harvest lowbush blueberry fruit. Can. J. Plant Sci. 52:701-705.

Agriculture and Agri-Food Canada. 2005. Crop profile for wild blueberry in Canada. Canada Pesticide Risk Reduction Program, Pest Management Center, Ottawa, Ontario, Canada.

Anonymous. 2011. Wild blueberry fact sheet C.4.2.0. Wild blueberry IPM weed management guide. New Brunswick Department of Agriculture, Aquaculture, and Fisheries, New Brunswick, Canada.

Barker, W.G. and W.B. Collins. 1963. Growth and development of the lowbush blueberry: Apical abortion. Can. J. Bot. 41:1319-1324.

Barker, W.G., I.V. Hall, L.E. Aalders, and G.W. Wood. 1964. The lowbush blueberry industry in eastern Canada. Econ. Bot. 18:357-365.

Barros, R.S. and S.J. Neill. 1987. Shoot growth in willow (Salix viminalis) in relation to abscisic acid, plant water status and photoperiod. Physiol. Plant. 70:708-712.

Bell, H.P. 1950. Determinate growth in the blueberry. Can. J. Res. 28:637-644.

Bell, H.P. 1953. The growth cycle of the blueberry and some factors of the environment. Can. J. Bot. $31: 1-6$.

Bell, H.P. and J. Burchill. 1955. Flower development in the lowbush blueberry. Can. J. Bot. 33: 251-258.

Benoit, G.R., W.J. Grant, A.A. Ismail, and D.E. Yarborough. 1984. Effect of soil moisture and fertilizer on the potential and actual yield of lowbush blueberry. Can. J. Plant Sci. 64:683689.

Bootsma, A. 1984. Forage crop maturity zonation in the Atlantic region using growing degreedays. Can. J. Plant Sci. 64:329-338.

Bowley, S.R. 2008. A hitchhikers guide to statistics in plant biology. Any old subject books. Guelph, Ontario, Canada.

Carlson, J.D. and J.F. Hancock, Jr. 1991. A methodology for determining suitable heat-unit requirements for harvest of highbush blueberry. J. Amer. Soc. Hort. Sci. 116:774-779.

Chiasson, G. and J. Argall. 1996. Pollination of wild blueberries. New Brunswick Department of Agriculture, Aquaculture, and Fisheries, 10 Jan. 2012. <http://www.gnb.ca/0171/10/ 0171100009-e.asp>.

Delbridge, R., D. Rogers, P. Burgess, and S. Wood. 2011. Insect and disease management schedule. Nova Scotia guide to pest management in wild blueberry. AgDex No. 235/605. AgraPoint Intl.

Dorado, J., E. Sousa, I.M. Calha, J.L. GonzálezAndújar, and C. Fernández-Quintanilla. 2008. Predicting weed emergence in maize crops under two contrasting climatic conditions. Weed Res. 49:251-260.

Eaton, E.L. and R.G. White. 1960. The relation between burning dates and the development of sprouts and flower buds in the lowbush blueberry. Proc. Amer. Soc. Hort. Sci. 76:338-342.

Eggert, F.P. 1957. Shoot emergence and flowering habit in the lowbush blueberry (Vaccinium angustifolium). Proc. Amer. Soc. Hort. Sci. 69:288-292. 
Glass, V.M. and D.C. Percival. 2000. Challenges facing the pollination and fruit set in indigenous blueberries (Vaccinium angustifolium Ait.). Fruit Var. J. 54:44-47.

Glass, V.M., D.C. Percival, and J.T.A. Proctor. 2005. Tolerance of lowbush blueberries ( $\mathrm{Vac}$ cinium angustifolium Ait.) to drought stress. I. Soil water and yield component analysis. Can. J. Plant Sci. 85:911-917.

Gordon, R. and A. Bootsma. 1993. Analyses of growing degree-days for agriculture in Atlantic Canada. Clim. Res. 3:169-176.

Hall, I.V. 1958. Some effects of light on native lowbush blueberries. Proc. Amer. Soc. Hort. Sci. 72:216-218.

Hall, I.V. and L.E. Aalders. 1961. Cytotaxonomy of lowbush blueberries in eastern Canada. Amer. J. Bot. 48:199-201.

Hall, I.V., L.E. Aalders, and W.G. Barker. 1964. A preliminary investigation of factors limiting lowbush blueberry production on Cape Breton Island. Can. J. Plant Sci. 44: 491-492.

Hall, I.V., L.E. Aalders, and K.B. McRae. 1982. Lowbush blueberry production in eastern Canada as related to certain weather data. Can. J. Plant Sci. 62:809-812.

Hall, I.V., L.E. Aalders, N.L. Nickerson, and S.P. Vander Kloet. 1979. The biological flora of Canada. 1. Vaccinium angustifolium Ait., sweet lowbush blueberry. Can. Field Nat. 93:415430.

Hall, I.V., F.R. Forsyth, and R.J. Newbery. 1970. Effect of temperature on flower bud and leaf anthocyanin formation in the lowbush blueberry. HortScience 5:272-273.

Hall, I.V. and R.A. Ludwig. 1961. The effects of photoperiod, temperature, and light intensity on the growth of the lowbush blueberry
(Vaccinium angustifolium Ait.). Can. J. Bot. 39:1733-1739.

Hoefs, M.E.G. and J.M. Shay. 1981. The effects of shade on shoot growth of Vaccinium angustifolium Ait. after fire pruning in southeastern Manitoba. Can. J. Bot. 59:166-174.

Izquierdo, J., J.L. González-Andújar, F. Bastida, J.A. Lezaún, and M.J. Sánchez del Arco. 2009. A thermal time model to predict corn poppy (Papaver rhoeas) emergence in cereal fields. Weed Sci. 57:660-664.

Jensen, K.I.N. 1985. Tolerance and residues of hexazinone in lowbush blueberries. Can. J. Plant Sci. 65:223-227.

Jensen, K.I.N. 2002. Response of lowbush blueberry (Vaccinium angustifolium Ait.) to hexazinone applied early in the fruiting year. Can. J. Plant Sci. 82:781-783.

Jensen, K.I.N. and D.E. Yarborough. 2004. An overview of weed management in the wild lowbush blueberry-Past and present. Small Fruits Rev. 3:229-255.

Junttila, O. 1976. Apical growth cessation and shoot tip abscission in Salix. Physiol. Plant. 38:278-286.

Kender, W.J. 1967. Rhizome development in the lowbush blueberry as influenced by temperature and photoperiod. Proc. Amer. Soc. Hort. Sci. 90:144-148.

Kender, W.J. 1968. Rest period in rhizome buds of lowbush blueberry, Vaccinium angustifolium Ait. Proc. Amer. Soc. Hort. Sci. 93:254-259.

Martinson, K., B. Durgan, F. Forcella, J. Wiersma, K. Spokas, and D. Archer. 2007. An emergence model for wild oat (Avena fatua). Weed Sci. 55:584-591.

Matlack, G.R., D.J. Gibson, and R.E. Good. 1993. Regeneration of the shrub Gaylussacia baccata and associated species after low-intensity fire in an Atlantic coastal plain forest. Amer. J. Bot. 80:119-126.

Millington, W.F. 1963. Shoot tip abortion in Ulmus Americana. Amer. J. Bot. 50:371-378.

NeSmith, D.S. and D.C. Bridges. 1992. Modelling chilling influence on cumulative flowering: A case study using 'Tifblue' rabbiteye blueberry. J. Amer. Soc. Hort. Sci. 117:698-702.

Nowland, J.L. and J.J. MacDougall. 1973. Soils of Cumb. Count. NS: Report No. 17. Nova Scotia Soil Survey. Canada Department of Agriculture. W.W. Friesen and Sons Ltd., Altma, Manitoba, Canada.

Smagula, J.M. and D.E. Yarborough. 2010. Lowbush blueberry nutrition series: Leaf \& soil sampling procedures. Fact Sheet No. 222. UMaine Ext. No. 2092. Univ. Maine Coop. Ext. 23 Jan. 2012. <http://umaine.edu/blueberries/factsheets/ production/wild-bluberry-nutrition-series-leafsoil-sampling-procedures/>.

Strik, B.C. and D. Yarborough. 2005. Blueberry production trends in North America, 1992 to 2003, and predictions for growth. HortTechnology 15:391-398.

Suzuki, T. 1991. Shoot-tip abscission and adventitious abscission of internodes in mulberry (Morus alba). Physiol. Plant. 82:483-489.

Trevett, M.F. 1962. Nutrition and growth of the lowbush blueberry. Maine Agr. Exp. Sta., Univ. Maine Bull. 605.

Webb, K.T., R.L. Thompson, G.J. Beke, and J.L. Nowland. 1991. Soils of Colchester County, Nova Scotia: Report No.19 Nova Scotia Soil Survey. Research Branch, Agriculture Canada, Ottawa, Ontario, Canada.

Wood, G.W. 1961. The influence of honeybee pollination on fruit set of the lowbush blueberry. Can. J. Plant Sci. 41:332-335. 